\title{
Análises de amostras de mel comercializados em feiras-livres da cidade de Barreiras-Bahia
}

\section{Analysis of honey samples sold in open-air markets in the city of Barreiras-Bahia}

\author{
Camila Filgueira de Souza ${ }^{1}$, Luana Regina Pereira Alves ${ }^{1}$, Fabrício Luiz Tulini ${ }^{2}$, Alexandra \\ Mara Goulart Nunes Mamede ${ }^{1}$, Diana de Meneses Souza ${ }^{1}$, Ana Celia Barreto de Araújo \\ Santana ${ }^{3}$, Ítalo Abreu Lima ${ }^{1 *}$
}

\begin{abstract}
RESUMO
Objetivou-se com essa pesquisa, avaliar através de análises químicas, físicas e físico-químicas, amostras de méis comercializados em feiras livres na cidade Barreiras-Bahia. As análises de proteína e lugol foram realizadas de forma qualitativa. Avaliou-se também: $\mathrm{pH}$, acidez titulável, atividade diastásica, açúcares redutores, sacarose aparente, hidroximetilfurfural (HMF), cinzas e umidade. A amostra MF1 não apresentou conteúdo proteico e apresentou coloração de verde a azul indicando a presença de dextrinas e amido, estando inadequada para comercialização. Os valores médios dos índices de pH e acidez apresentaram variação estatística e estão dentro do intervalo de limites permitidos segundo as normas brasileiras. A amostra MF2 indicou o mais alto teor de sacarose aparente. As amostras (MF4 e MF5), apresentaram teores de HMF superior ao estipulado, o que indica manipulação ou período de armazenamento inadequado. Algumas das amostras de mel, sem inspeção, comercializadas nas feiras livres da cidade de Barreiras, não atendem aos padrões exigidos pela legislação Brasileira de mel.
\end{abstract}

Palavras-chave: Qualidade; Mel; Feiras-livres.

\section{ABSTRACT}

The objective of this research was to evaluate through chemical, physical and physical-chemical analyses, samples of honey sold in open markets in the city of Barreiras-Bahia. Protein and lugol analyzes were performed qualitatively. It was also evaluated: $\mathrm{pH}$, titratable acidity, diastase activity, reducing sugars, apparent sucrose, hydroxymethylfurfural (HMF), ash and moisture. The MF1 sample did not have protein content and showed a green to blue color indicating the presence of dextrins and starch, being unsuitable for commercialization. The mean values of $\mathrm{pH}$ and acidity indices showed statistical variation and are within the range of limits allowed according to Brazilian standards. The MF2 sample indicated the highest apparent sucrose content. The samples (MF4 and MF5) presented HMF contents higher than stipulated, which indicates inadequate handling or storage period. Some of the honey samples, without inspection, sold in open markets in the city of Barreiras, do not meet the standards required by the Brazilian honey legislation.

Keywords: Quality; Honey; Free fairs.

\footnotetext{
${ }^{1}$ Instituto Federal de Educação, Ciência e Tecnologia da Bahia - IFBA, Campus Barreiras, Brasil

*E-mail: italoabreu@ifba.edu.br

${ }^{2}$ Universidade Federal do Oeste da Bahia - Campus Reitor Edgard Santos

${ }^{3}$ Instituto Federal de Educação, Ciência e Tecnologia da Bahia - IFBA, Campus Lauro de Freitas, Brasil
} 


\section{INTRODUÇÃO}

O mel é um produto alimentício natural, utilizado pela população desde o antigo Egito, como fonte de alimento e na medicina popular, devido as suas propriedades antioxidante, cicatrizante, expectorante, ação sedativa, analgésica e anti-inflamatória, além de possuir atividade antibacteriana. $\mathrm{O}$ aumento do consumo de mel pela população, associada à prática da apicultura, tem-se demonstrado uma atividade promissora e rentável para os produtores e para a economia do Brasil (SILVA et al., 2018; ESCOBAR; XAVIER, 2013).

De acordo com a legislação brasileira, mel é um produto naturalmente produzido por abelhas melíferas e é obtido a partir do néctar das flores, de secreções de partes viva s de plantas ou de excreções de insetos sugadores de partes vivas de plantas. É composto por uma solução de açúcares concentrados, principalmente glicose e frutose, os quais influenciam diretamente sua doçura, além de possuir enzimas (invertase, amilase e glicooxidase), aminoácidos, ácidos orgânicos, minerais, pigmentos e grãos de pólen (BRASIL, 2000). Por possuir diferentes origens florais, sua composição físico-química e sensorial pode sofrer algumas variações e, assim, ser classificado de acordo com sua origem botânica e forma de obtenção (BRASIL, 2000).

Em virtude da busca pelo consumo de produtos naturais, o consumo de mel tem aumentado significativamente em todo o mundo (BERTOLDI, 2008). Esta procura tem impulsionado melhorias na qualidade do mel produzido, visando à segurança alimentar através de um produto natural, livre de contaminantes e microrganismos e, assim, a aceitação do mesmo no mercado internacional.

No entanto, o aumento do mercado consumidor de mel está esbarrando no problema de adulteração do produto. O mel é um produto natural de fornecimento limitado e frequentemente, de alto preço, tem sido alvo de adulterações, causando extrema desconfiança nos consumidores tradicionais, sendo a principal barreira para a ampliação de seu consumo (AZAREDO et al., 2003). O mel pode ser alvo da adição de substâncias adulterantes, como açúcar comercial, ocasionando a diminuição da qualidade do produto (SILVA et al., 2018).

No entanto, essas fraudes e outras alterações que o mel pode apresentar, são facilmente detectadas por análises em laboratório. A obtenção de parâmetros físicoquímicos de méis é importante para sua caracterização como também é primordial para 
garantir a qualidade desse produto no mercado (DE SOUZA et al., 2021; NASCIMENTO et al., ALVES et al., 2020).

No Brasil, as análises físico-químicas indicadas pela legislação para o controle de qualidade do mel puro são: umidade, acidez, cinzas, açúcares redutores e não-redutores, açúcares totais, $\mathrm{pH}$, cor, sólidos insolúveis em água, atividade diastásica e hidróximetilfurfural (HMF) (BRASIL, 2000).

Os méis artesanais se diferenciam dos méis industriais em alguns aspectos, são eles referentes às operações decorrentes no processo, colheita, centrifugação e envase. A embalagem e o rótulo representam um fator de confiabilidade e seguridade para o consumidor. Estratégias mercadológicas, quanto à publicidade e logística, são ferramentas necessárias também ao produto artesanal, visando promoção e qualidade do mesmo (DE SOUZA et al., 2021; SOUZA, 2019; SEBRAE, 2011).

Em feiras livres na cidade de Barreiras-BA os méis artesanais são comercializados em garrafa PET reutilizada de diferentes volumes. Os recipientes são dispostos em bancadas, sob condição de temperatura ambiente e incidência de luz solar. Diferentes fornecedores suprem as demandas dos feirantes, reduzindo assim as certezas dos padrões de qualidade e uniformidade do produto (NASCIMENTO et al., ALVES et al., 2020).

A definição de parâmetros físico-químicos de amostras de méis é importante para sua caracterização, e primordial para garantir a qualidade deste produto no mercado, além de poder determinar o grau de maturidade, pureza e deterioração (Ribeiro et al., 2009).

Alguns estudos vem demostrando a qualidade de méis comercializados em feiraslivres em vários estados brasileiros (NASCIMENTO et al., ALVES et al., 2020; RIBEIRO \& STARIKOFF, 2019; SOUZA, 2019; SILVA et al., 2018; BORGES et al., 2017).

Dessa forma, objetivou-se com a essa pesquisa, avaliar através de análises físicas, químicas e físico-químicas, a qualidade de méis comercializados em feiras livres na cidade Barreiras-Bahia.

\section{METODOLOGIA}


O presente estudo foi realizado no Laboratório de Análise de Alimentos do Instituto Federal da Bahia - IFBA, campus Barreiras e no Laboratório de Bromatologia da Universidade Federal do Oeste da Bahia - UFOB, campus Barreiras.

Foram coletadas 5 amostras de méis, sendo dois lotes de cada, totalizando 10 amostras analisadas. As amostras de méis foram obtidas em duas feiras livres da cidade de Barreiras - Bahia, sendo posteriormente transportadas e conservadas sob temperatura ambiente, desde a compra até o momento das análises, sendo mantidas nas embalagens de origem e ao abrigo da luz solar até serem utilizadas para análises, a fim de evitar qualquer tipo de alteração. Os méis foram identificados da seguinte maneira: MF1, MF2, MF3, MF4 e MF5.

As análises de proteína e lugol foram realizadas de forma qualitativas para analisar a genuinidade ou não das amostras de méis. Para verificar a qualidade dos méis, foram realizadas análises quantitativas de: $\mathrm{pH}$, acidez titulável, atividade diastásica, açúcares redutores, sacarose aparente, hidroximetilfurfural (HMF), cinzas (minerais), e umidade. Todas as análises foram conduzidas, segundo metodologia de Adolfo Lutz (IAL, 2008).

O teste Lugol foi aplicado para avaliar a presença de amido nas amostras de mel, segundo o método 0184/IV, no qual $10 \mathrm{~g}$ de amostra foram diluídos em $20 \mathrm{~mL}$ de água destilada e levados à ebulição, seguidos de arrefecimento e depois adicionados de $0,5 \mathrm{~mL}$ de solução de Lugol. A presença de amido foi evidenciada por uma cor azul nas amostras.

A presença/ausência de proteína foi determinada por um teste qualitativo, a partir da adição de $1 \mathrm{~g}$ de mel, $15 \mathrm{~mL}$ de água e $5 \mathrm{~mL}$ de ácido tânico, que atua na formação do precipitado proteico, em proveta de $25 \mathrm{~mL}$. A solução foi deixada em repouso por 24 horas em temperatura ambiente, observando em seguida à matéria precipitada.

A atividade de água foi determinada em aparelho Aqualab CX2. Para a determinação das viscosidades dos méis foi utilizado um viscosímetro da marca Brookfield, modelo RVT.

As análises estatísticas foram realizadas com duas repetições. Os dados foram interpretados por meio da análise de variância (ANOVA) e, quando necessário, as médias foram comparadas utilizando-se o teste de Tukey, a 5\% de probabilidade. As análises estatísticas foram realizadas no software Statistical Analysis System (SAS) (SAS Institute Inc., Cary, NC, USA), licenciado para a Universidade Federal de Lavras (UFLA). 


\section{RESULTADOS E DISCUSSÃO}

Os resultados dos testes qualitativos estão descritos na Tabela 01 e indicam a genuinidade ou não das amostras. As reações de Lund e Lugol são consideradas análises qualitativas e complementares que podem indicar adulteração ou má conservação do mel.

Tabela 01. Resultados qualitativos de parâmetros químicos das análises de Proteínas (Reação de Lund) e Reação Lugol de amostras de méis comercializadas em feiras livres da cidade de Barreiras-Ba.

\begin{tabular}{cccccc}
\hline Parâmetros & \multicolumn{5}{c}{ Amostras de Méis } \\
\cline { 2 - 6 } Analisados & MF1 & MF2 & MF3 & MF4 & MF5 \\
\hline Reação de Lund & - & + & + & + & + \\
Reação de Lugol & + & - & - & - & - \\
\hline Os símbolos (-) e (+), indicam ausência e presença ou negativo e positivo, respectivamente, & col \\
conforme cada análise apresentada na tabela. Fonte: Elaboração própria (2021).
\end{tabular}

O conteúdo de proteína qualifica o mel como um produto legítimo, deste modo, a ausência desse nutriente indica não só adulteração, mas também um produto distinto do mel de abelha. O mel floral deve apresentar quantidade média de $0,3 \mathrm{~g} / 100 \mathrm{~g}$ do produto. No entanto, a análise de cunho qualitativo teve a finalidade de verificar presença ou ausência de proteína nas amostras de méis analisadas.

De acordo com a Reação de Lund, todas as amostras apresentaram conteúdo proteico, sinalizando que estas foram identificadas como méis, com exceção da MF1, que não apresentou alguma quantidade de proteína, se mostrando em desconformidade com a regulamentação vigente.

A reação de Lugol está relacionada à pureza do mel, utilizando iodo e iodeto de potássio (Lugol), que na presença de amido e dextrinas no mel é responsável pela formação de cor característica (IAL, 2008). Gomes et al., (2017), afirmam que este teste indica a presença de dextrinas e amido, sendo considerado positivo quando a coloração final for violeta ou azul.

De acordo com a Tabela 01, todas as amostras não apresentaram coloração avermelhada, sendo consideradas negativas para Reação de Lugol, indicando assim que amostras de méis comercializadas em feiras livres na cidade Barreiras não foram adulteradas com adição de amido, com a exceção da amostra MF1, que apresentou 
coloração de verde a azul indicando a presença de dextrinas e amido, estando inadequada para comercialização.

Os resultados das amostras de méis comercializadas em feiras livres do município de Assis Chateaubriand, Paraná foram negativos para a pesquisa de Reação de Lugol, uma vez que as mesmas mantiveram-se inalteradas, de acordo com Silva et al., (2018).

Ribeiro \& Starikoff, (2019), realizaram análises físico-químicas em 22 amostras de méis de abelhas de diferentes municípios da Região Sul do país. Apenas dez amostras tinham registro de inspeção, o restante não era inspecionadas. Os autores constataram que na reação de Lund, 9,09\% das amostras (5 e 6) não formaram precipitado, caracterizando amostras de méis adulterados e em relação a reação de Lugol, as amostras (6 e 18) apresentaram coloração marrom - avermelhada, sendo consideradas positivas devido a uma possível adição de glicose comercial ou xaropes de açúcar.

Os resultados obtidos nas análises físico-químicas de atividade de água (Aw), umidade, cinzas e viscosidade das amostras de méis comercializadas em feiras livres na cidade de Barreiras- BA estão apresentados na Tabela 02, a seguir.

O índice de atividade de água (Aw) indica a quantidade de água livre, que de tal modo estará disponível para as reações bioquímicas e físico-químicas, bem como processos biológicos deteriorantes.

Tabela 02: Valores médios de parâmetros físico-químicos das análises de atividade de água (Aw), umidade, cinzas e viscosidade de amostras de méis comercializadas em feiras livres da cidade de Barreiras-Ba.

\begin{tabular}{ccccc}
\hline Amostras & \multicolumn{4}{c}{ Parâmetros Físico-Químicos } \\
\cline { 2 - 5 } de Méis & Aw & Umidade (\%) & Cinzas (\%) & Viscosidade (cP) \\
\hline MF1 & - & - & - & - \\
MF2 & $0,618^{a}$ & $20,2^{a}$ & $0,035^{d}$ & $2.390^{c}$ \\
MF3 & $0,600^{c}$ & $18,6^{c}$ & $0,138^{c}$ & $3.620^{a}$ \\
MF4 & $0,602^{b}$ & $19,2^{b}$ & $0,326^{a}$ & $1.990^{d}$ \\
MF5 & $0,599^{d}$ & $17,9^{d}$ & $0,279^{b}$ & $2.553^{b}$ \\
\hline
\end{tabular}

Médias seguidas pela mesma letra não diferem $(\mathrm{P}>0,05)$ entre si pelo teste de Tukey na mesma coluna. Fonte: Elaboração própria (2021).

A amostra de mel MF2, conforme mostra a tabela 1, apresentou índice de atividade de água de 0,618 , que difere significativamente das demais amostras $(P \geq 0,05)$, ultrapassando o limite de quantidade de água livre inibitório para o crescimento microbiológico, tornando assim essa amostra mais susceptível à ocorrência de processos 
fermentativos por ação de leveduras. Enquanto as demais amostras de méis apresentam diferença significativa entre si e valores dentro do intervalo considerado inibitório para crescimento microbiológico.

Não existem na Legislação Brasileira valores limite para atividade de água em méis, no entanto, considera-se que valores de atividade de água até 0,60 sejam limitantes para inibir multiplicação de qualquer microrganismo (FRANCO, 2005).

De Assis Carvalho et al., (2020), obtiveram valores entre 0,519 a 0,647 para atividade água de amostras de mel não inspecionadas na região metropolitana de Belo Horizonte.

O conteúdo de água no mel é uma das características mais importantes e constitui o segundo componente em quantidade. Por se tratar de uma substância densa concentrada de açúcares, o mel é altamente higroscópico e absorve água com facilidade em ambientes com umidade relativa superior a 60\% (BOGDANOV, 2010). Os valores de umidade estabelecidos pela Legislação Brasileira para mel é de até $20 \%$ ou 20 g de umidade/ $100 \mathrm{~g}$ de mel analisado (BRASIL, 2000).

Os resultados apresentados nesse estudo correspondem à Legislação, conforme observado na Tabela 01, exceto para a amostra MF2, que ultrapassou ligeiramente $(20,2 \%)$ o teor de umidade permitido. Essa amostra, como mencionado anteriormente, também demonstrou um índice de atividade de água elevado, evidenciando a correlação entre os respectivos parâmetros.

Silva et al., (2018), analisaram as propriedades físico-químicas de cinco amostras de méis comercializadas em feiras livres do município de Assis Chateaubriand, Paraná e concluíram que apenas uma amostra apresentou alto valor de umidade $(28,71 \%)$.

Em 2010, Pereira avaliou que os méis apresentaram valores percentuais médios de umidade estatisticamente diferentes entre algumas das espécies de amostras analisadas no Brasil, porém não houve diferença comparando-se as espécies de abelha produzindo mel em diferentes locais. Isso mostra que o percentual de água no mel é uma característica intrínseca da espécie produtora, não havendo influência significativa da região de origem.

Quanto ao teor de cinzas, refere-se diretamente ao conteúdo de resíduos minerais fixo presente no mel. A regulamentação brasileira estabelece que o limite máximo permitido seja até $0,6 \%$ de cinzas (BRASIL, 2000).

Conforme os resultados apresentados, as amostras analisadas não apresentaram valores acima do permitido, permanecendo em conformidade com a Legislação 
Brasileira. Os valores obtidos em cada amostra tiveram grande divergência entre si, o que pode ser explicado pela diferença do material coletado pelas abelhas, durante o processo de alimentação, além das diferenças de manejo e colheita do mel pelos apicultores (FINOLA, LASAGNO \& MARIOLI, 2007).

Não existe na Instrução Normativa No 11, um valor mínimo para o teor de cinzas em mel de abelha, porém supõe-se que valores muitos baixos para este parâmetro podem indicar a adição de adulterantes, solubilizando a real fração de resíduo mineral fixo. Por meio da análise de cinzas é possível determinar algumas irregularidades no mel, como por exemplo, a falta de higiene e a não decantação e/ou filtração no final do processo de retirada do mel pelo apicultor (VILHENA; ALMEIDA-MURADIAN, 1999).

Amostras de mel produzidas no município de Assis Chateaubriand, Paraná e analisadas por Silva et al., (2018), também apresentaram valores de cinza dentro do limite estabelecido pela legislação.

As propriedades reológicas de um alimento o caracterizam também nutricional e sensorialmente. A viscosidade afeta diretamente na qualidade do mel e está associada à umidade e temperatura sofrida no processamento desse alimento. Além disso, exerce impacto sobre qual o modelo de equipamento a ser utilizado para a manipulação do produto. A maioria dos méis se comporta como fluido Newtoniano, sua importância se dá no fato do condicionamento do processo de extração, bombeamento, processamento e envase do produto (NASCIMENTO, 2012).

As amostras analisadas tiveram variação do valor médio do coeficiente de viscosidade entre $1.990 \mathrm{cP}$ (centipoise) e $3.620 \mathrm{cP}$, esses valores equivalem à 1,99 Pa.s e 3,62 Pa.s, respectivamente, evidenciando a variação estatística entre as amostras $(P \geq 0,05)$. A viscosidade do mel remete a sua densidade relativa, logo, quanto menor o conteúdo de água, maiores os índices de densidade e viscosidade. Apesar de ser um parâmetro importante em relação à qualidade do mel, não possui critério de avaliação para viscosidade nas legislações vigente (ALVES et al., 2005).

Silva (2016), afirma que o processo de cristalização ocorre espontaneamente, já que à temperatura ambiente, o mel é uma solução supersaturada de glicose, sendo esta convertida em glicose mono-hidratada. Logo, a cristalização é um fenômeno indesejado, pois altera sua textura, tornando-o menos atraente para o consumidor. 
Os resultados obtidos nas análises físico-químicas de acidez titulável e pH de méis comercializadas em feiras livres na cidade de Barreiras- BA estão apresentados na Tabela 03.

Tabela 03: Valores médios de parâmetros físico-químicos das análises de acidez titulável e pH de amostras de méis comercializadas em feiras livres da cidade de Barreiras-Ba.

\begin{tabular}{ccc}
\hline $\begin{array}{c}\text { Amostras } \\
\text { de Méis }\end{array}$ & \multicolumn{2}{c}{ Parâmetros Físico-Químicos } \\
\cline { 2 - 3 } MF1 & pH & AT (mEq/Kg) \\
MF2 & $3,30^{e}$ & $28,50^{a}$ \\
MF3 & $3,90^{c}$ & $11,80^{e}$ \\
MF4 & $3,67^{d}$ & $14,88^{d}$ \\
MF5 & $3,88^{b}$ & $20,47^{b}$ \\
& $3,99^{a}$ & $16,12^{c}$ \\
\hline
\end{tabular}

Médias seguidas pela mesma letra não diferem $(\mathrm{P}>0,05)$ entre si pelo teste de Tukey na mesma coluna. Fonte: Elaboração própria (2021).

$\mathrm{O}$ pH é um parâmetro adimensional que define a capacidade de dissociação dos íons $\mathrm{H}^{+}$de um analito, definido como potencial hidrogeniônico. A Legislação Brasileira (2000) e o Codex Alimentarius (2001), estabelecem limites de pH entre 3,30-4,60 e 3,406,10 , respectivamente.

Os valores médios dos índices de $\mathrm{pH}$ dos méis, apresentam-se dentro do intervalo de limites permitidos segundo as normas brasileiras, sendo que as amostras apresentaram resultados diferentemente significativos.

Valores de $\mathrm{pH}$ muito baixos favorecem o crescimento de fungos e reduzem a vida útil do mel. Nesse contexto, Gomes et. al, (2017) avaliaram que amostras de mel de Jandaíra e de Apis melífera apresentaram pH abaixo do mínimo estabelecido pela Legislação Brasileira. Baixos valores de pH podem indicar a ocorrência de fermentação ou adulteração do produto.

Borges et al., (2017), analisando a qualidade de méis comercializados em feiras livres de Salvador e Petrolina, encontraram valores de $\mathrm{pH}$ variando de 3,6 a 4,1 para amostras de Petrolina e de 3,2 a 4,0 para as amostras de Salvador.

Pelo Codex Alimentarius (1993) são permitidos até 50mEq/Kg de acidez no mel utilizando $\mathrm{NaOH}$, já pela Legislação Brasileira (BRASIL, 2000) são permitidos, dentro do limite máximo, $40 \mathrm{mEq} / \mathrm{Kg}$, em se tratando do parâmetro acidez livre.

Os valores médios exibidos na Tabela 03, demonstram que o índice de acidez dos méis analisados apresentaram variação estatística e estão em conformidade, pois não 
ultrapassam 40mEq/Kg, como propõe a Legislação. Esse parâmetro é um importante indicativo de qualidade, pois a acidez do mel contribui para inibir a ação de microrganismos, além de acrescentar às características organolépticas e sensoriais do produto, bem como atividade antioxidante.

De Assis Carvalho et al., (2020), constataram a irregularidade em três amostras de mel não inspecionadas na região metropolitana de Belo Horizonte. Já Borges et al., (2017), constataram a irregularidade em duas amostras coletadas na cidade de SalvadorBA, nas quais apresentaram valores acima de $50 \mathrm{mEq} . \mathrm{kg}-1$, e para as amostras coletadas em Petrolina-PE os valores da acidez variaram entre 14,1 e 45,5 mEq.kg-1, que se aproximam dos resultados do presente estudo.

Em relação aos índices de açúcar redutor e sacarose aparente dos méis comercializadas em feiras livres na cidade de Barreiras- BA, os valores encontrados estão apresentados na Tabela 04.

Tabela 04: Valores médios de parâmetros físico-químicos das análises de açúcares redutores e sacarose aparente de amostras de méis comercializadas em feiras livres da cidade de BarreirasBa.

\begin{tabular}{ccc}
\hline Amostras & \multicolumn{2}{c}{ Parâmetros Físico-Químicos } \\
\cline { 2 - 3 } de Méis & Açúcar Redutor (\%) & Sacarose aparente (\%) \\
\hline MF1 & - & - \\
MF2 & $70,10^{d}$ & $5,5^{a}$ \\
MF3 & $73,20^{b}$ & $0,9^{d}$ \\
MF4 & $71,60^{c}$ & $2,1^{c}$ \\
MF5 & $74,15^{a}$ & $3,8^{b}$ \\
\hline
\end{tabular}

Médias seguidas pela mesma letra não diferem $(\mathrm{P}>0,05)$ entre si pelo teste de Tukey na mesma coluna. Fonte: Elaboração própria (2021).

A Legislação Brasileira separa e distingue em suas classificações os valores mínimos de açúcares redutores em relação ao mel floral e mel de melato ou misto. Sendo que o valor mínimo para méis de abelha exigidos pelos padrões é de 60\% (BRASIL, 2000).

Os valores médios do teor de açúcares redutores de méis comercializados em feiras livres indicaram diferença significativa entre as amostras analisadas. Silva (2016) menciona que o mel contém frutose e glicose (60 - 85\%) como monossacarídeos predominantes, além de maltose e sacarose como os mais importantes dissacarídeos. Desse modo as amostras obedecem aos valores correspondentes à norma em vigor. 
Pereira (2010), avaliou que os percentuais de açúcares redutores, no Brasil, nos estados da Bahia e de São Paulo, variaram significativamente entre amostras de méis das diferentes espécies.

A sacarose aparente, em que os valores são apresentados na Tabela 04, é um parâmetro complementar a açúcares redutores, pois os resultados são obtidos a partir da diferença de açúcares totais e açúcares redutores contidos em cada analito. Dessa forma é possível quantificar dissacarídeos, majoritariamente a sacarose, que posteriormente são hidrolisados em meio ácido aquecido, para então sofrer processo de titulometria semelhante à técnica citada anteriormente (ALMEIDA-MURADIAN et al., 2014).

A Legislação Brasileira permite que no máximo $6 \%$ do conteúdo do mel floral seja composto por sacarose (BRASIL, 2000). Quando os valores obtidos ultrapassam a média estimada, significa que o mel foi colhido prematuramente e os oligossacarídeos e dissacarídeos que seriam convertidos à glicose e frutose por ação enzimática permanecem em sua estrutura anterior. Outra possibilidade que explica o excesso de sacarose é a adulteração por adição de xarope de sacarose parcialmente invertida (GRANATO \& NUNES, 2016).

De acordo com Silva (2016), entre os dissacarídeos, a sacarose representa um papel importante na qualidade do mel, em que valores superiores a 5\% podem indicar a sua adulteração ou sua colheita precoce, estando em desacordo com a legislação.

A amostra MF2 indicou o mais alto teor de sacarose aparente (5,5\%), combinado com outros parâmetros em desacordo analisados anteriormente, supõe-se a possibilidade de um produto adicionado de outras soluções ou xaropes, barateando o custo e conferindo a essa amostra certa probabilidade de ser adulterada.

Bera (2004) observou que o teor de sacarose no mel puro manteve a média aproximada de $1,44 \%$ quando comparado ao mel adicionado de própolis, 1,45\%. Pereira (2007), analisou por titulometria, em mel do nordeste paraense que a sacarose aparente encontrada foi de $5,23 \% \pm 0,72$, comparada a outro método.

$\mathrm{Na}$ Tabela 05, são apresentados os valores dos parâmetros físico-químicos de atividade diastásica e hidroximetilfurfural, dos méis comercializadas em feiras livres na cidade de Barreiras- BA. 
Tabela 05: Valores médios de parâmetros físico-químicos das análises de atividade diastásica e hidroximetilfurfural de amostras de méis comercializadas em feiras livres da cidade de BarreirasBa.

\begin{tabular}{ccc}
\hline \multirow{2}{*}{$\begin{array}{c}\text { Amostras } \\
\text { de Méis }\end{array}$} & \multicolumn{2}{c}{ Parâmetros Físico-Químicos } \\
\cline { 2 - 3 } MF1 & Atividade diastásica & Hidroximetilfurfural (mg/kg) \\
MF2 & - & - \\
MF3 & $5,5^{a} \pm 0,2$ & $3,4^{d}$ \\
MF4 & $5,2^{b} \pm 0,3$ & $39,3^{c}$ \\
MF5 & $4,6^{c} \pm 0,1$ & $89,7^{b}$ \\
\hline
\end{tabular}

Médias seguidas pela mesma letra não diferem $(\mathrm{P}>0,05)$ entre si pelo teste de Tukey na mesma coluna. Fonte: Elaboração própria (2021).

O índice de diastase é, assim como o índice de HMF, um valor de extrema relevância para verificação da qualidade físico-química do mel, pois essas técnicas são direcionadas especificamente ao tratamento desse produto. Vargas \& Almeida (2013), ressalvam que esse parâmetro evidencia a atividade ou inatividade de enzimas presentes naturalmente no mel. Somente tratamentos térmicos agressivos inadequados e irregulares ao mel de abelha, ou o armazenamento por tempo muito extenso podem inativar a atuação de enzimas amilases, que desnaturam quando submetidas a temperaturas acima de $60{ }^{\circ} \mathrm{C}$.

A diastase é um conjunto de enzimas amilolíticas termolábeis que catalisam a hidrólise do amido em dextrina e maltose (NUNES, et al., 2012). A legislação exige um mínimo de diastase de 8 na escala Göthe ou 3 se o teor de HMF não ultrapassar $15 \mathrm{mg} / \mathrm{Kg}$ (BRASIL, 2000).

Nenhuma das amostras correspondeu estatisticamente ao valor exigido pela vigilância brasileira. Isso não implica que as amostras avaliadas não são méis ou foram adulteradas, mas indica que todas as amostras sofreram durante o processamento, e/ou transporte, e/ou armazenamento, condições de temperatura inadequadas. Entre essas etapas estão incluídos o transporte e armazenamento realizados durante a presente pesquisa. Os valores médios do índice de diástase das amostras de feira variaram entre 1,5 e 5,5 (Tabela 05), na escala Göthe.

Santos e Palma (2019) observaram que os resultados dos valores da atividade diastásica (escala Göthe) obtidos em amostras de mel de diferentes tipos e origens encontraram-se distribuídas entre 12 e 33 para méis de laranjeira, que apresentaram as atividades mais baixas; 40 e 81 para méis de eucalipto, que apresentaram as atividades mais elevadas; e entre 11 e 35 para os méis silvestres. 
O índice de diastase é um dos parâmetros mais importantes para evidenciar a qualidade do mel, sua relevância principal para o mel é que ela é mais sensível ao calor que a invertase, no entanto, seus resultados devem ser avaliados juntos aos resultados de outros parâmetros como, teor de hidroximetilfurfural, sendo feita uma avaliação conjunta, averiguando se há altos teores de HMF.

O HMF é oriundo de dois tipos de transformações, sendo que uma delas pode ser acelerada em meio ácido e a outra sob condições de aquecimento, desidratação de hexoses e Reação de Mailard, respectivamente. O 5-hidroximetil-furano-2-carbaldeído quando metabolizado em excesso é considerado tóxico para consumo humano, mas os méis manipulados adequadamente não apresentam quantidade suficiente que ponha em risco a saúde ou confira toxicidade (MARCHINI, MORETI \& OTSUK, 2005).

A Legislação Brasileira regulamenta que para manter o Padrão de Qualidade e Identidade do mel comercializado, o limite estabelecido de HMF deve ser equivalente à até $60 \mathrm{mg} / \mathrm{Kg}$ (BRASIL, 2000). Quando o mel é armazenado em condições adequadas, ou seja, ao abrigo de luz e temperaturas de até $20^{\circ} \mathrm{C}$, os níveis de $\mathrm{HMF}$ permanecem aceitáveis. Portanto existe uma correlação entre o teor de HMF e o tempo de estocagem (GRANATO \& NUNES, 2016).

As amostras de méis MF2 e MF3, apresentaram valores médios correspondentes à norma vigente (Tabela 05). As outras amostras analisadas (MF4 e MF5), apresentaram teores de HMF superior ao estipulado, o que indica manipulação ou período de armazenamento inadequado.

Nunes, Cruz e Franco (2012), obtiveram que os valores de HMF encontrados entre as amostras foram do máximo de $11,32 \mathrm{mg} / \mathrm{Kg}$ a não detectado. No qual demonstrou que todas as onze amostras ficaram com as concentrações bem a abaixo do limite estipulado pela Legislação Brasileira.

\section{CONCLUSÃO}

As amostras de mel, sem algum tipo de inspeção (Municipal, Estadual ou Federal) comercializadas nas feiras livres da cidade de Barreiras, demonstraram menor seguridade e correspondência aos padrões exigidos pela Vigilância Brasileira. Esse fato não anula a existência de méis de alta qualidade comercializados em feira-livre, no entanto, a falta de 
fiscalização e de selo de inspeção, fazem com que esses méis apresentem qualidade inferiores tratando-se de suas propriedades físico-químicas.

Duas amostras de méis (MF2 e MF3) com 3,4mg/Kg e 39,3mg/Kg, apresentaramse em conformidade quanto ao teor de HMF. A amostra MF1 é a única que em duas repetições não apresentou alguma quantidade de proteína, sendo desqualificada como mel.

Nenhuma das amostras apresentou índice de atividade diastásica correspondente ao valor regulamentado, esses resultados indicam tratamento inadequado nas etapas póscolheita, como condições elevadas de temperatura ou estoque por períodos extensos.

Sugere-se para trabalhos futuros, a avaliação do mel não inspecionado, comercializado em todas as feiras livres e pequenos mercados da cidade de Barreiras, a fim de verificar possíveis adulterações. Recomenda-se o uso de métodos instrumentais, especialmente os baseados em cromatografia e técnicas de espectroscopia, para identificar os tipos de adulterações.

\section{AGRADECIMENTOS}

Os autores agradecem ao Instituto Federal de Educação, Ciência e Tecnologia da Bahia, Campus Barreiras, por seu apoio financeiro.

\section{REFERÊNCIAS}

ALVES, L. R. P. Análise de Qualidade e Levantamento dos Perfis dos Produtores, Comerciantes e Consumidores de Mel da Cidade de Barreiras - Ba. 2021. 65f. Trabalho de conclusão de curso (Graduação) - Instituto Federal de Educação, Ciência e Tecnologia da Bahia, Campus Barreiras, Curso de Engenharia de Alimentos, 2021.

ALVES, R.M.; CARVALHO, C.A.L.; SOUZA, B.A.; SODRÉ, G.S.; MARCHINI, L.C. Características físico-químicas de amostras de mel de melipona mandacaia smith (hymenoptera: apidae). Ciência e Tecnologia de Alimentos, Campinas, 25(4): 644650, out.- dez. 2005.

AZEREDO, L. C. et al. Protein contents and physicochemical properties in honey samples of Apis mellifera of different floral origins. Food Chemistry, v. 80, n. 2, p. 249$254,2003$. 
BERTOLDI, C. R. C. Meliponicultura, uma alternativa sustentável. Embrapa. Agosto de 2008.

BOGDANOV, S. The Book of Honey: physical properties of honey. Bee Product Science, chapter 4, January, 2010.

BORGES, J. G., PINHEIRO, J. V. R., DE ANDRADE, R. B., \& TELLES, C. P. Qualidade de mel comercializado em feiras livres de Salvador e Petrolina. Revista Brasileira de Produtos Agroindustriais, Campina Grande, v. 19, n. 3, p. 231-240, 2017.

BRASIL. Ministério da Agricultura. Instrução normativa ${ }^{\circ}$ 11, de 20 de outubro de 2000. Estabelece o regulamento técnico de identidade e qualidade do mel. Diário Oficial da República Federativa do Brasil, Poder Executivo, Brasília, DF, 23 out. 2000.

DE SOUZA, C. F., ALVES, L. R. P., TULINI, F. L., MAMEDE, A. M. G. N., DE ARAÚJO SANTANA, A. C. B., \& LIMA, Í. A. Parâmetros de qualidade de méis inspecionados comercializados na cidade de Barreiras-Bahia. Research, Society and Development, v. 10, n. 1, p. e28710110959-e28710110959, 2021.

DE SOUZA, C. F. Avaliação físico-química de méis artesanais e industrializados comercializados na cidade de Barreiras - BA. 2019. 47f. Trabalho de conclusão de curso (Graduação) - Instituto Federal de Educação, Ciência e Tecnologia da Bahia, Campus Barreiras, Curso de Engenharia de Alimentos, 2019.

DE ASSIS CARVALHO, Raíssa et al. Assessment of adulteration and mycoflora identification of honey samples marketed in the metropolitan region of Belo Horizonte, Brazil. Research, Society and Development, v. 9, n. 7, p. 440974246, 2020.

ESCOBAR, ALS; XAVIER, FB. Propriedades fitoterápicas do mel de abelhas. Rev Uningá, Maringá, n.37, p.159 - 172, 2013.

FRANCO, B. D. G. M.; LANDGRAF, M. Microbiologia dos alimentos. São Paulo: Atheneu, 2005.

FINOLA, M. S., LASAGNO, M. C., \& MARIOLI, J. M. Microbiological and chemical characterization of honeys from central Argentina. Food Chemistry, v. 100, n. 4, p. 1649-1653, 2007.

INSTITUTO ADOLFO LUTZ. Métodos físico-químicos para análise de alimentos. Coordenadores Odair Zenebon, Neus Sadocco Pascuet e Paulo Tiglea - São Paulo: Instituto Adolfo Lutz, edição IV, p. 330-332, 2008.

GRANATO, D.; NUNES, D. Análises químicas, propriedades funcionais e controle de qualidade de alimentos e bebidas: uma abordagem teórico-prática. Elsevier Brasil, 2017.

GOMES, V. V., DOURADO, G. S., COSTA, S. C., LIMA, A. K. O., SILVA, D. S., BANDEIRA, A. M. P., ... \& TAUBE, P. S. Avaliação da qualidade do mel comercializado no Oeste do Pará, Brasil. Revista Virtual de Química, Pará, v. 9, n. 2, p.815-826, 06 fev. 2017.

MARCHINI, L. C.; MORETI, A. C. C. C.; OTSUK, I. P. Análise de agrupamento, com base na composição físico-química, de amostras de méis produzidos por Apis mellifera 
L. no Estado de São Paulo. Ciência e Tecnologia de Alimentos, v. 25, n. 1, p. 8-17, 2005.

NASCIMENTO, A. M. da S.; SOUZA, I. B. de; SANTOS, R. R. dos; Ciências, tecnologia e inovação [livro eletrônico]: do campo à mesa. In: ALVES, L. R. P.; SOUZA, C. F. de; SANTANA, A. C. B. de A.; TULINI, F. L.; LIMA, Í. A. Qualidade de méis comercializados em feiras livres no município de Barreiras-Ba. $1^{\text {a }}$ ed. Recife PE. Instituto Internacional Despertando Vocações, 2020. 789 - 806.

NASCIMENTO, Diana. Parâmetros de Avaliação da Qualidade do Mel e Percepção do Risco pelo Consumidor. 2012. 88 f. Dissertação (Mestrado) - Curso de Engenharia Agronómica, FCUP/FCNAUP, Portugal, 2012.

NUNES, M. E. M.; CRUZ, L. C.; FRANCO, J. L. Análise quantitativa de hidroxinetilfurfural em méis produzidos no município de São Gabriel - RS. Centro Universitário Franciscano Unifra, São Gabriel, v. -, n. -, p.1-2, 16 set. 2012.

PEREIRA, L. L. Análise físico-química de amostras de méis de Apis mellifera e Meliponíneos. 2010. 85 f. Dissertação (Mestrado) - Curso de Engenharia Agrônoma, Escola Superior de Agricultura "Luiz de Queiroz", Universidade de São Paulo, Piracicaba, 2010.

RIBEIRO, R.; STARIKOFF, K. R. Avaliação da qualidade físico-química e microbiológica de mel comercializado. Revista de Ciências Agroveterinárias, v. 18, n. 1, p. 111-118, 2019.

SANTOS, K. S.; PALMA, M. S. CINÉTICA DA DIÁSTASE EM MÉIS DE DIFERENTES ORIGENS FLORAIS: Um novo protocolo experimental. Apacame, Rio Claro, v. 70, n. 1, p.1-4, 10 out. 2019.

SEBRAE - Nacional - Manual de Segurança e Qualidade para Apicultura. $1^{\mathrm{a}}$ ed. Brasília, 2009.

SILVA, M. G. C. D., FIGUEIRA, P. T., HOSCHEID, J., \& FUKUMOTO, N. M. Análise das propriedades físico-químicas de amostras de mel comercializado em feiras livres do município de Assis Chateaubriand, PR. Higiene Alimentar, v. 32, n. 278/279, 2018.

SILVA, Vanelle Maria da. Redes neurais artificiais e modelos de regressão na predição de propriedades reológicas de méis brasileiro. 2016. 153 f. Tese (Doutorado) - Curso de Ciência dos Alimentos, Universidade Federal de Lavras, Lavras, 2016.

VILHENA, F.; ALMEIDA-MURADIAN, L. B. Análises físico-químicas de méis de São Paulo. Mensagem Doce, v. 53, p. 17-19, 1999.

Recebido em: 20/10/2021

Aprovado em: 21/11/2021

Publicado em: 27/11/2021 